\title{
Effects of Temperature and Oxygen Potential on Removal of Sulfur from Desulfurization Slag
}

\author{
Akitoshi MATSUI, ${ }^{1 *}$ Yu-ichi UCHIDA, ${ }^{2)}$ Naoki KIKUCHII) and Yuji MIKI ${ }^{3)}$ \\ 1) Steelmaking Research Department, Steel Research Laboratory, JFE Steel Corporation, 1 Kokan-cho, Fukuyama, $721-8510$ \\ Japan. $\quad 2$ ) Steelmaking Research Department, Steel Research Laboratory, JFE Steel Corporation. Now at Nippon Insti- \\ tute of Technology, 4-1 Gakuendai, Miyashiro-cho, Saitama, 345-8501 Japan. \\ 3) Principal Researcher, Steel Research Laboratory, JFE Steel Corporation, 1 Kawasaki-cho, Chuo-ku, Chiba, $260-0835$ Japan. \\ (Received on December 28, 2016; accepted on February 20, 2017; originally published in Tetsu-to- \\ Hagané, Vol. 102, 2016, No. 10, pp. 553-559)
}

\begin{abstract}
The effects of temperature (1 373-1673 K) and oxygen potential on removal of sulfur from hot metal desulfurization slag were investigated in laboratory-scale experiments. Both $\mathrm{CaS}$ and $\mathrm{CaSO}_{4}$ exist as sulfur compounds in hot metal desulfurization slag. CaS can be removed under the condition of higher oxygen potential, whereas $\mathrm{CaSO}_{4}$ can be removed at a lower oxygen potential. Thus, in order to remove both CaS and $\mathrm{CaSO}_{4}$ from desulfurization slag, it is important to control the temperature and oxygen potential to the optimum values. In this study, a higher sulfur removal ratio exceeding $90 \%$ was obtained under the conditions of a temperature range of $1473-1673 \mathrm{~K}$ and oxygen potential range of $10^{-3}-10^{-8} \mathrm{~atm}$. These results were in good agreement with thermodynamic calculations.

In order to confirm the possibility of reusing desulfurization slag as flux after sulfur removal, hot metal desulfurization experiments were carried out with a $70 \mathrm{~kg}$-scale laboratory furnace. At the same $\mathrm{CaO}$ amount in the desulfurization flux, [S] content at 900 seconds after flux addition was approximately equal to that when using virgin flux. The effect of $\mathrm{SiO}_{2}$ contamination due to slag recycling on the desulfurization rate constant $K$ was also estimated.

From these experimental results, it may be suggested that removal of sulfur from desulfurization slag is an effective approach for constructing a slag recycling system.
\end{abstract}

KEY WORDS: desulfurization slag; slag recycle; hot metal pretreatment.

\section{Introduction}

In recent years, progressively higher quality and functionality have been demanded in steel products. For example, strict quality requirements are applied to properties such as ductility, low-temperature toughness, weldability and resistance to hydrogen-induced cracking in thick plates for construction and shipbuilding and linepipe for transportation of oil and natural gas. An ultra-low sulfur content is indispensable in steel products because $\mathrm{MnS}$ which forms as sulfide inclusions in steel is known to act as a starting point of hydrogen-induced cracking. The hot metal desulfurization process has been widely adopted in industrial operations to meet the demand for ultra-low sulfur steel.

As a hot metal desulfurization process, a mechanical stirring method employing a rotating impeller with addition of $\mathrm{CaO}$ based flux ${ }^{1)}$ has been adopted in many companies. It has been reported that sulfur is distributed only at the surrounding edge of the slag particles in the EPMA mapping image of desulfurization slag after treatment. ${ }^{2}$ In order to obtain high desulfurization efficiency, increasing the reac-

\footnotetext{
* Corresponding author: E-mail: a-matsui@jfe-steel.co.jp DOI: http://dx.doi.org/10.2355/isijinternational.ISIJINT-2016-748
}

tion area by using the desulfurization flux blasting method ${ }^{2)}$ and promoting flux entrainment by using a bottom inclination vessel ${ }^{3)}$ have been developed and are contributing to reducing the cost of desulfurization and amount of slag generation.

Although the applications of steelmaking slag have expanded to use in roadbed materials as a result of various developments, ${ }^{4)}$ use of desulfurization slag is limited to cement raw materials due to its higher $\mathrm{CaO}$ content, and this is not necessarily a high value-added application. Therefore, a technique for cooling and crushing desulfurization slag, followed by separation of the iron content by screening/magnetic selection, and recycling as a sintering material has been developed. ${ }^{5)}$ Furthermore, a technique for recycling desulfurization slag as a desulfurization flux in the hot metal desulfurization process has also been developed with the aims of reducing the desulfurization cost and slag generation. ${ }^{6}$ However, the amount of desulfurization slag that can be recycled in the steel works by these techniques is limited due to the insufficient exhaust gas desulfurization ability in the sintering process and insufficient desulfurization capacity in the hot metal desulfurization process due to the buildup of sulfur in the slag with repeated recycling.

If sulfur can be efficiently removed from desulfurization 
slag, it is possible to expand the amount of slag recycling in the steel works as a $\mathrm{CaO}$ based flux, with no restrictions on the $\mathrm{S}$ content. Mori et al. $^{7)}$ reported the results of desulfurization experiments from $\mathrm{CaO} / \mathrm{SiO}_{2}=1-3$ reagent synthetic slag assuming blast furnace slag and converter slag at $1823 \mathrm{~K}$ in an oxygen or Ar atmosphere. Kobayashi et al. ${ }^{8,9)}$ conducted desulfurization experiments from $\mathrm{CaO}-\mathrm{Al}_{2} \mathrm{O}_{3}-$ $\mathrm{CaF}_{2}$ based slag generated in the secondary refining process. These experiments were performed at $1173-1373 \mathrm{~K}$ in an $\mathrm{Ar}-\mathrm{O}_{2}$ atmosphere, and showed the possibility that sulfur in the slag can be removed as $\mathrm{SO}_{2}$ by oxidation treatment. However, there are few studies on sulfur removal from slag, and no experimental results in connection with hot metal desulfurization slag have been reported.

Therefore, in this study, a fundamental investigation of the effects of the treatment temperature and oxygen potential on removal of sulfur from hot metal desulfurization slag was carried out, and experiments in which the desulfurized slag (hereinafter, sulfur removal slag) was recycled to the hot metal desulfurization process were conducted.

\section{Experimental Procedure}

\subsection{Sulfur Removal from Slag Experiments}

A schematic diagram of the experimental apparatus used in the slag desulfurization experiments is shown in Fig. 1. The temperature in the electric furnace was controlled to a predetermined value $(1373-1673 \mathrm{~K})$, and the oxygen potential in the furnace was adjusted with air or a $\mathrm{CO}$ / $\mathrm{CO}_{2}$ mixture gas at a flow rate of $2 \mathrm{~L} / \mathrm{min}$. After adjusting the oxygen potential in the furnace, an alumina crucible (95mass\% $\mathrm{Al}_{2} \mathrm{O}_{3}-3$ mass $\% \mathrm{SiO}_{2}$, width: $17 \mathrm{~mm}$, height: 12 $\mathrm{mm}$, length: $80 \mathrm{~mm}$ ) containing $3 \times 10^{-3} \mathrm{~kg}$ of slag pulverized to the particle size of $0.25 \times 10^{-3} \mathrm{~m}$ or less was placed in the electric furnace and held for 60 minutes. Kobayashi et al. $\left.{ }^{89}\right)$ considered the mechanism of sulfur removal from desulfurization slag containing $\mathrm{CaF}_{2}$ by heat treatment experiments for 60 minutes. Therefore, following the experimental conditions of Kobayashi et al., the heat treatment time in this study was also set to 60 minutes to enable a reliable evaluation of the removal ratio of sulfur from slag. The temperature in the furnace was measured by a thermocouple and kept constant during experiment. The $\mathrm{CO} / \mathrm{CO}_{2}$ ratios of the mixed gas were $0.003,0.03$, and 0.3 . A CaS reagent (purity of $99.99 \%$ ) or $\mathrm{CaSO}_{4}$ reagent (purity of $98 \%$ ) or hot metal desulfurization slag (sulfur content: 2-3 mass\%) was used as a slag sample. The slag sample was taken from the furnace after 60 minutes and cooled

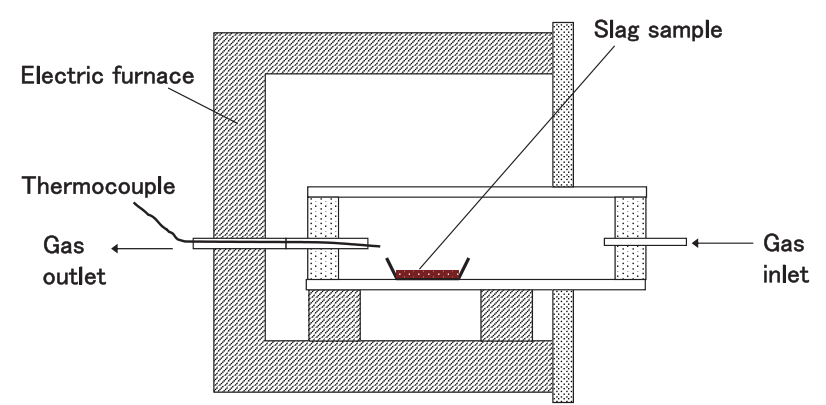

Fig. 1. Experimental apparatus in slag desulfurization experiments. (Online version in color.) rapidly in order to analyze its chemical composition. When the slag in the alumina crucible was observed visually after the experiments, the slag was substantially in a solid state under all the experimental conditions in this study. Based on the sulfur content in the slag before and after the experiment, the removal ratio of sulfur was evaluated by Eq. (1).

$$
\text { removal ratio of sulfur }(\%)=\frac{(\text { mass } \% S)_{0}-(\text { mass } \% S)_{f}}{(\text { mass } \% S)_{0}}
$$

where, $(\operatorname{mass} \% \mathrm{~S})_{0}$ : sulfur content in slag before experiment and $(\operatorname{mass} \% \mathrm{~S})_{\mathrm{f}}$ : sulfur content in slag after experiment.

\subsection{Sulfur Removal Slag Recycling Experiments}

A schematic diagram of the experimental apparatus used in the hot metal desulfurization experiments with the sulfur removal slag is shown in Fig. 2. Table $\mathbf{1}$ summarizes the experimental conditions. A magnesia refractory was constructed in a high frequency induction furnace by magnesia stamping. The inner diameter (bath diameter) was $0.25 \mathrm{~m}$ and the bath depth was $0.20 \mathrm{~m} .70 \mathrm{~kg}$ of hot metal was melted in the furnace, and the metal composition was adjusted to $[\mathrm{mass} \% \mathrm{C}]=4.5 \%$, $[\mathrm{mass} \% \mathrm{~S}]=0.028 \%$. After adjusting the metal composition, a graphite impeller was

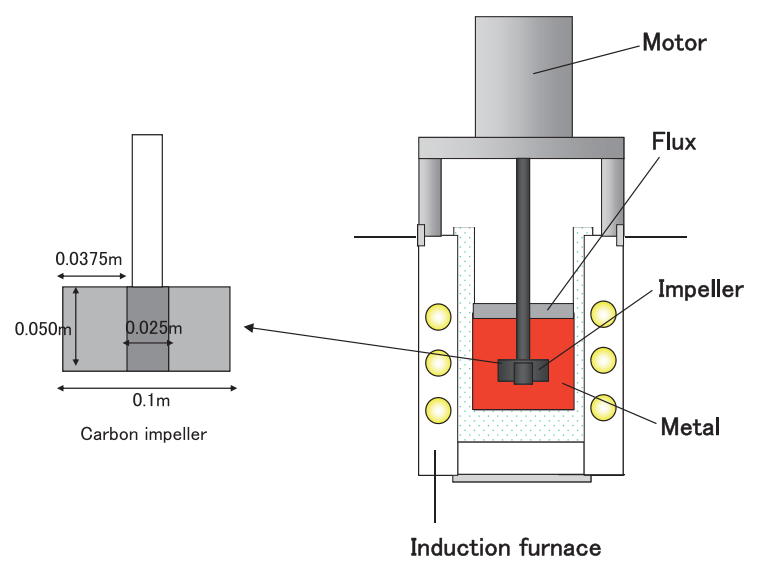

Fig. 2. Experimental apparatus in hot metal desulfurization experiments. (Online version in color.)

Table 1. Experimental conditions of hot metal desulfurization experiments.

\begin{tabular}{lllcc}
\hline No. & & & $\mathrm{H}-1$ & $\mathrm{H}-2$ \\
\hline Metal & Weight & $\mathrm{kg}$ & 70 & 70 \\
& {$[\mathrm{mass} \% \mathrm{C}]$} & $\mathrm{mass} \%$ & 4.5 & 4.5 \\
& {$[\mathrm{mass} \% \mathrm{~S}]$} & $\mathrm{mass} \%$ & 0.028 & 0.028 \\
& Temperature & $\mathrm{K}$ & 1573 & 1573 \\
\hline Flux & Virgin flux & $\mathrm{kg} / \mathrm{t}$-metal & - & 5.1 \\
& $\begin{array}{l}\text { Desulfurization slag after } \\
\text { slag desulfurization }\end{array}$ & $\mathrm{kg} / \mathrm{t}-\mathrm{metal}$ & 7.5 & - \\
& Weight of CaO & $\mathrm{kg} / \mathrm{t}-\mathrm{metal}$ & 5.0 & 5.0 \\
\hline Impeller & Rotation speed & $\mathrm{rpm}$ & 700 & 700 \\
& Immersion depth & $\mathrm{m}$ & 0.1 & 0.1 \\
\hline Experimental time & $\mathrm{sec}$ & 900 & 900 \\
\hline
\end{tabular}


immersed in the hot metal and rotated by a driving motor. The impeller immersion depth, defined as the distance from the still hot metal surface to the top side of the impeller, was set at $0.1 \mathrm{~m}$. The impeller rotation speed was controlled by voltage and was set to $700 \mathrm{rpm}$ by adjustment with a rotation speed measurement device. The rotation speed in this experiment was determined so that the stirring energy by mechanical stirring calculated by the following Eqs. (2)-(7) was equivalent to that in the actual plant.

$$
\begin{aligned}
& P=N_{P} \cdot \rho \cdot n^{3} \cdot d^{5} \\
& N_{P}=\frac{a}{\operatorname{Re}}+B\left(\frac{10^{3}+1.2 \operatorname{Re}^{0.66}}{10^{3}+3.2 \operatorname{Re}^{0.66}}\right)^{p} \times\left(\frac{Z}{D}\right)^{(0.35+2 b / D)} \ldots \\
& a=14+(2 b / D) \times\left\{670 \cdot(d / D-0.6)^{2}+185\right\} \\
& B=10^{\left\{1.3-4 \cdot(2 b / D-0.5)^{2}-1.14(d / D)\right\}} \\
& p=1.1+4(2 b / D)-2.5(d / D-0.5)^{2}-7(2 b / D)^{4} . \\
& \operatorname{Re}=\rho \cdot n \cdot d^{2} / \mu
\end{aligned}
$$

where, $P$ : stirring energy $(\mathrm{W}), N_{P}$ : power number $(-), \rho$ : density of liquid $\left(\mathrm{kg} / \mathrm{m}^{3}\right), n$ : rotation speed $(1 / \mathrm{s}), d$ : diameter of impeller (m), Re: Reynolds number $(-), a, B, p$ : proportional constants $(-), D$ : diameter of vessel $(\mathrm{m}), Z$ : bath depth (m), $b$ : height of impeller (m) and $\mu$ : viscosity of liquid $(\mathrm{Pa} \cdot \mathrm{s})$.

After achieving the set rotation speed, desulfurization flux pulverized to the particle size of $0.25 \times 10^{-3} \mathrm{~m}$ or less was added to the hot metal. Hot metal samples were taken at predetermined intervals during the experiment to investigate the desulfurization behavior. In No. H-1, the desulfurization slag after sulfur removal treatment (sulfur removal slag) was used as the desulfurization flux. In No. $\mathrm{H}-2$, virgin $\mathrm{CaO}$ based flux was used. $\mathrm{CaO}$ consumption was set to $5.0 \mathrm{~kg} / \mathrm{t}-$ metal in both experiments. The hot metal temperature was controlled in the range of $1573 \pm 10 \mathrm{~K}$ during the experiments. The impeller was stopped at 900 seconds after flux addition, and the impeller was removed, completing the experiment.

\section{Experimental Results}

\subsection{Experimental Results of Sulfur Removal from CaS and $\mathrm{CaSO}_{4}$ Reagents}

The X-ray diffraction pattern (XRD; SmartLab, Rigaku) of the hot metal desulfurization slag used in identification of the sulfur compounds is shown in Fig. 3. Both CaS and $\mathrm{CaSO}_{4}$ existed as sulfur compounds in the hot metal desulfurization slag. Based on the relationship shown in Eq. (8), the existence ratio of $\mathrm{CaS}$ and $\mathrm{CaSO}_{4}$ in the slag changes according to the oxygen potential. It is considered that $\mathrm{CaSO}_{4}$ increases as the oxygen potential increases. In order to remove sulfur from hot metal desulfurization slag, it is necessary to confirm the forms of the sulfur compounds in the slag and control the oxygen potential appropriately on that basis.

$$
\mathrm{CaS}+2 \mathrm{O}_{2}(g)=\mathrm{CaSO}_{4}
$$

To improve the sulfur removal ratio from the hot metal desulfurization slag, it is necessary to clarify the conditions of sulfur removal from both the compounds $\mathrm{CaS}$ and $\mathrm{CaSO}_{4}$. Firstly, therefore, the oxygen potential required for removal of sulfur from the $\mathrm{CaS}$ and $\mathrm{CaSO}_{4}$ reagents was investigated. The experimental results of the relationship between the oxygen potential and the sulfur removal ratio from the reagents after holding at $1573 \mathrm{~K}$ for 60 minutes are shown in Fig. 4. The oxygen potential was calculated from the $\mathrm{CO} / \mathrm{CO}_{2}$ ratio and temperature in each experiment by using thermodynamic data ${ }^{11)}$ of the following Eqs. (9) and (10).

$$
\begin{gathered}
\mathrm{O}_{2}(g)+2 \mathrm{CO}(g)=2 \mathrm{CO}_{2}(g) . \\
\Delta G_{9}^{o}=-568020+175.540 \mathrm{~T}
\end{gathered}
$$

where, $T$ : temperature $(\mathrm{K})$. The removal ratio of sulfur from the $\mathrm{CaS}$ reagent increases as the oxygen potential increases under the condition of a constant temperature. On the other hand, it was found that the sulfur removal ratio from the $\mathrm{CaSO}_{4}$ reagent improves at a lower oxygen potential. From

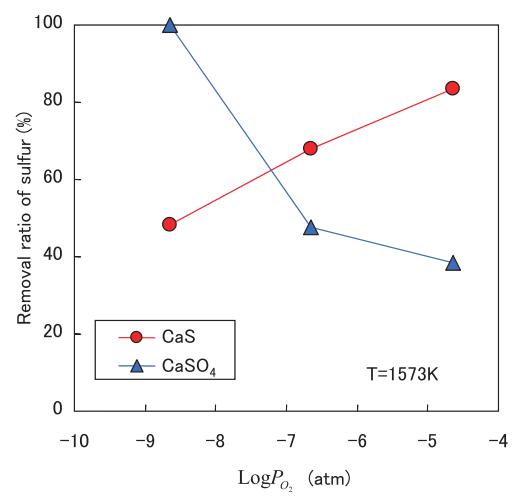

Fig. 4. Removal ratio of sulfur from $\mathrm{CaS}$ and $\mathrm{CaSO}_{4}$ reagents. (Online version in color.)

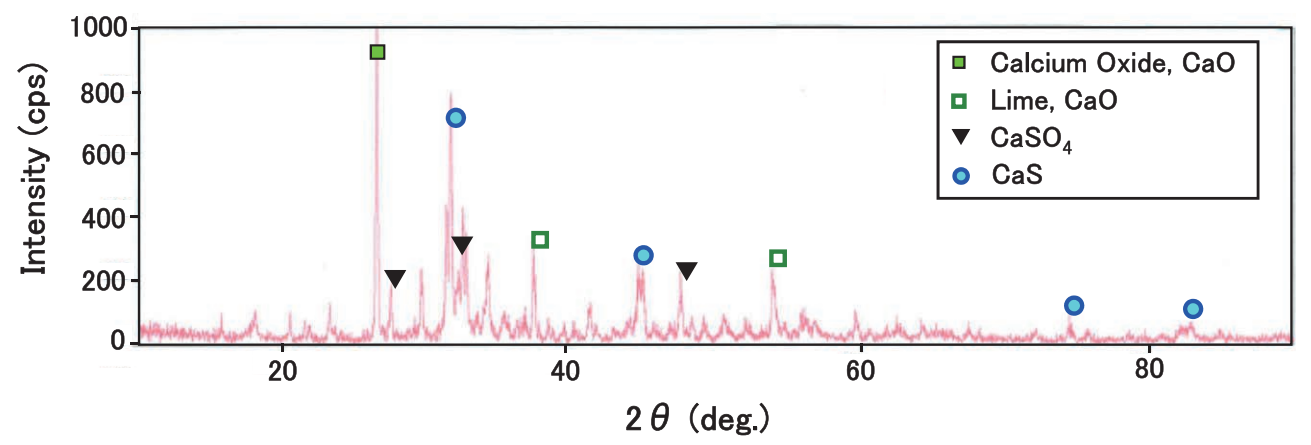

Fig. 3. X-ray diffraction pattern of hot metal desulfurization slag. (Online version in color.) 
the following Eqs. (11) and (12), it is estimated that the sulfur in $\mathrm{CaS}$ and $\mathrm{CaSO}_{4}$ is vaporized as $\mathrm{SO}_{2}$ gas.

$$
\begin{gathered}
(\mathrm{CaS})+\frac{3}{2} \mathrm{O}_{2}=(\mathrm{CaO})+\mathrm{SO}_{2} \\
\left(\mathrm{CaSO}_{4}\right)=(\mathrm{CaO})+\mathrm{SO}_{2}+\frac{1}{2} \mathrm{O}_{2}
\end{gathered}
$$

Therefore, in order to improve the sulfur removal ratio from hot metal desulfurization slag, it is necessary to find conditions under which the sulfur removal ratios from both the $\mathrm{CaS}$ and $\mathrm{CaSO}_{4}$ compounds increase.

\subsection{Experimental Results of Sulfur Removal from Hot Metal Desulfurization Slag}

The experimental results of the relationship between the oxygen potential and the sulfur removal ratio from hot metal desulfurization slag after holding at $1373-1673 \mathrm{~K}$ for 60 minutes are shown in Fig. 5. Under the condition of $1373 \mathrm{~K}$, the sulfur removal ratio from the slag was limited to less than $70 \%$. It was found that a sulfur removal ratio exceeding $90 \%$ could be obtained under the conditions of a temperature range of $1473-1673 \mathrm{~K}$ and an oxygen potential range of $10^{-3}-10^{-8} \mathrm{~atm}$. Although the sulfur removal ratio from the slag in the air improved as the temperature increased, the sulfur removal ratio was $89 \%$ even at $1573 \mathrm{~K}$ and $1623 \mathrm{~K}$. If all the sulfur compounds in the slag in this research are $\mathrm{CaS}$, it is considered that almost all the sulfur in the slag can be removed as $\mathrm{SO}_{2}$ gas at $1623 \mathrm{~K}$ in the air. Therefore, in this study, it is estimated that the remaining $11 \%$ of the sulfur in the slag is attributable to $\mathrm{CaSO}_{4}$.

It was found that a higher sulfur removal ratio from hot metal desulfurization slag containing a mixture of both $\mathrm{CaS}$ and $\mathrm{CaSO}_{4}$ compounds was obtained under the conditions of a temperature range of 1473-1 $673 \mathrm{~K}$ and an oxygen potential range of $10^{-3}-10^{-8} \mathrm{~atm}$.

\subsection{Experimental Results of Hot Metal Desulfurization by Reusing Sulfur Removal Slag as Desulfuriza- tion Flux}

As the necessary conditions for sulfur removal from hot metal desulfurization slag were determined in the previous section, next, hot metal desulfurization experiments in which the slag after sulfur removal was reused as the desulfurization flux were carried out in the laboratory furnace. It

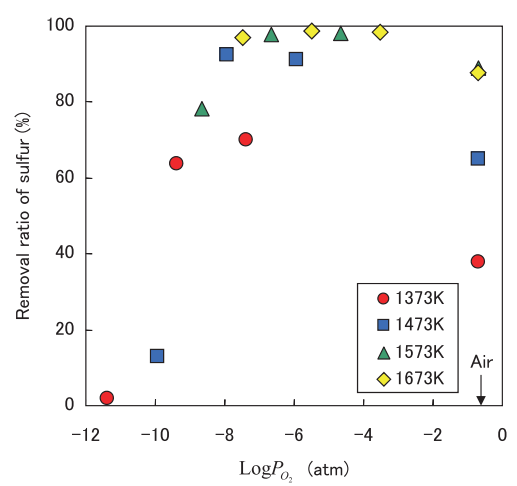

Fig. 5. Removal ratio of sulfur from hot metal desulfurization slag at various temperatures and oxygen potentials. (Online version in color.) is expected that consumption of virgin $\mathrm{CaO}$ based flux for hot metal desulfurization treatment and the amount of slag generated in the steel works can be reduced by reusing hot metal desulfurization slag with a low sulfur content.

The sulfur removal slag in this experiment was prepared by removing sulfur from hot metal desulfurization slag at the temperature of $1573 \mathrm{~K}$ and oxygen potential of $10^{-4.6}$ atm. The time change in the sulfur content in the hot metal desulfurization experiments in the laboratory furnace is shown in Fig. 6. Although the desulfurization rate until 240 seconds is slightly lower when using the sulfur removal slag (No. H-1), the sulfur content after 900 seconds is substantially the same as that when using the virgin flux (No. H-2). As shown in Table 1, the amount of $\mathrm{CaO}$ in the flux was adjusted to be the same in both experiments. It is considered that the sulfur removal slag obtained by treating hot metal desulfurization slag at the appropriate temperature and oxygen potential can be reused as flux for the hot metal desulfurization process.

\section{Discussion}

\subsection{Effect of Temperature on Sulfur Removal}

The temperature dependence of the sulfur removal ratio from hot metal desulfurization slag is shown in Fig. 7. At $1573 \mathrm{~K}$ or more, the effect of the $\mathrm{CO} / \mathrm{CO}_{2}$ ratio is small and a relatively high sulfur removal ratio exceeding $78 \%$ was obtained. On the other hand, at $1473 \mathrm{~K}$ or less, the sulfur removal ratio shows a rapid increase in temperature dependency, and the effect of the $\mathrm{CO} / \mathrm{CO}_{2}$ ratio also increases. Kobayashi et $a l .{ }^{9)}$ investigated the relationship between the

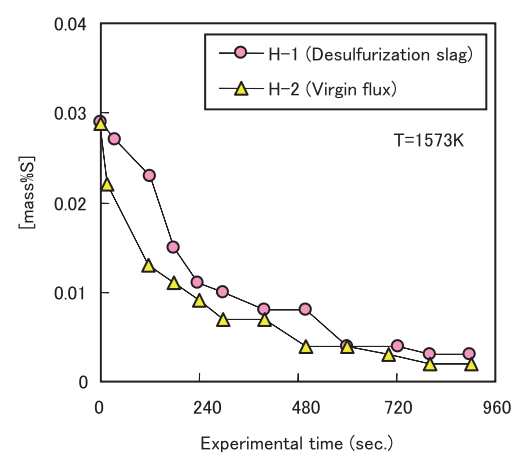

Fig. 6. Change in $[\mathrm{S}]$ content in hot metal desulfurization experiments. (Online version in color.)

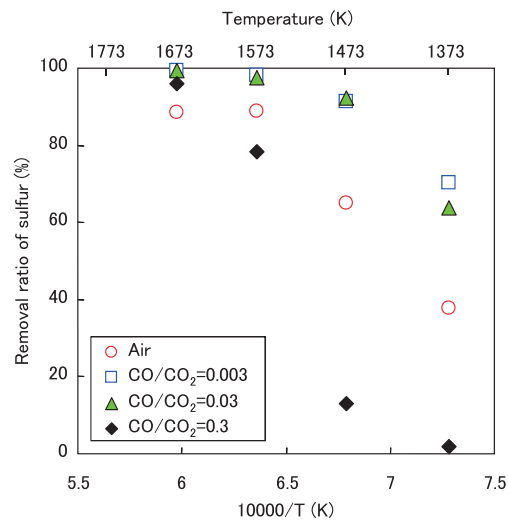

Fig. 7. Effect of temperature on removal ratio of sulfur from desulfurization slag. (Online version in color.) 
sulfur removal ratio from slag and temperature, and reported that the sulfur removal ratio decreases as the treatment temperature decreases due to the formation of $\mathrm{CaSO}_{4}$ in the slag by the reaction in Eq. (8), which results in $\mathrm{CaSO}_{4}$ remaining in the slag. As in the report by Kobayashi et al., it is also considered that the reaction in Eq. (8) is possible under the condition of lower temperature using air of this study. On the other hand, in the temperature range of $1373-1473 \mathrm{~K}$, the sulfur removal ratio is the lowest at the low oxygen potential of $\mathrm{CO} / \mathrm{CO}_{2}=0.3$. Since this behavior cannot be explained by Eq. (8), a more detailed analysis, such as investigation of the form of the sulfur compounds in the slag after treatment, is required. However, lower temperature treatment is considered preferable for reducing the cost and energy consumption of the slag recycling process utilizing sulfur removal slag. Lower temperature treatment with an appropriate oxygen potential is necessary for a highly competitive slag recycling process.

\subsection{Thermodynamic Calculation of Sulfur Removal Condition}

As shown in the experiments with the reagents in section 3.1 , the relationship between the sulfur removal ratio from $\mathrm{CaS}$ and $\mathrm{CaSO}_{4}$ and the oxygen potential has an inverse correlation, and it was estimated that the sulfur in $\mathrm{CaS}$ and $\mathrm{CaSO}_{4}$ was vaporized as $\mathrm{SO}_{2}$ gas according to Eqs. (11), (12).

On the other hand, according to the experimental results with hot metal desulfurization slag in Fig. 5, a higher sulfur removal ratio was obtained at $1473 \mathrm{~K}$ or more in the oxygen potential range of $10^{-3}-10^{-8}$ atm. As shown in Fig. 3, although both $\mathrm{CaS}$ and $\mathrm{CaSO}_{4}$ exist in the hot metal desulfurization slag, it is expected that sulfur can be removed from both of these sulfur compounds in these temperature and oxygen potential ranges. In order to evaluate the sulfur removal behavior quantitatively, thermodynamic calculations of the stable sulfur phase were carried out with FACT Database/Factsage ${ }^{\mathrm{TM}} 6.1$ software. $^{12,13)}$ The calculation results are shown in Fig. 8. The experimental results of sulfur removal from hot metal desulfurization slag were also plotted in Fig. 8. The open marks indicate the sulfur removal ratio of $<90 \%$, and the solid marks indicate a ratio of $\geqq 90 \%$. From the calculation results, it can be seen that

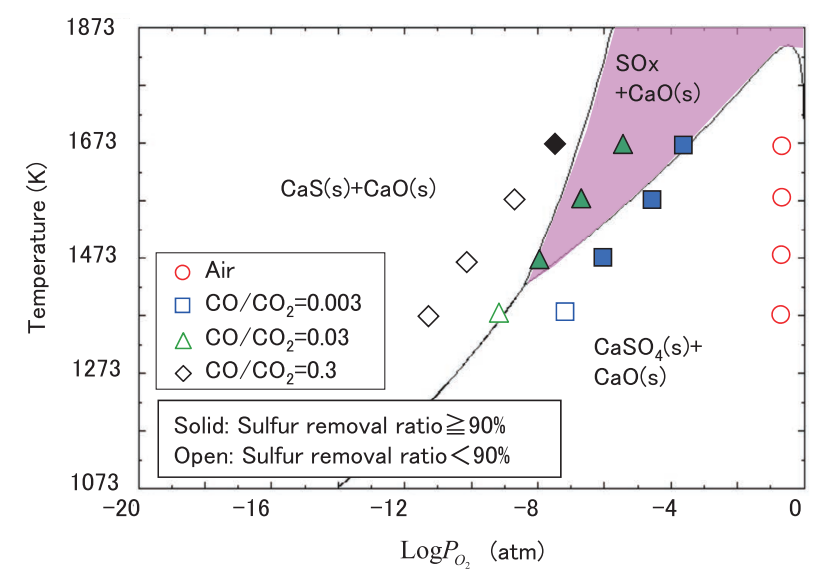

Fig. 8. Thermodynamic calculations of stable sulfur phase. (Online version in color.) there is a temperature and oxygen potential region for $\mathrm{SO}_{\mathrm{X}}$ gas stabilization (shaded area in Fig. 8). The conditions for the sulfur removal ratio exceeding $90 \%$ roughly coincided with this region. It has been reported that the minimum value of sulfur solubility in $\mathrm{CaO}-\mathrm{Al}_{2} \mathrm{O}_{3}-\mathrm{SiO}_{2}$ slag occurs in the oxygen potential range of $10^{-4}-10^{-6}$ atm at $1773 \mathrm{~K}$ and $\mathrm{P}_{\mathrm{SO} 2}=2 \%$. ${ }^{14)}$ This tendency approximately agrees with the experimental results and the thermodynamic calculations in Fig. 8. That is, the optimum temperature and oxygen potential for sulfur removal from hot metal desulfurization slag can be explained quantitatively by a thermodynamic consideration.

Here, let us consider the reaction between the hot metal desulfurization slag and gaseous phase. In this study, a kinetic analysis of sulfur removal from hot metal desulfurization slag is not possible due to the constant holding time of 60 minutes at the specified temperature and atmosphere. However, since the thermodynamic equilibrium shown in Fig. 8 can generally explain the experimental results, the sulfur removal rate is estimated to be comparatively large. Research on the $\mathrm{SO}_{2}$ gas absorption performance of limestone has shown that porous limestone has a higher $\mathrm{SO}_{2}$ absorption rate. ${ }^{15)}$ Nakai et al. ${ }^{2)}$ showed that hot metal desulfurization slag has a comparatively porous property because it is generated in the hot metal desulfurization process by using $\mathrm{CaO}$-based flux. A typical example of an EPMA mapping image of slag after sulfur removal treatment is shown in Fig. 9. It can be observed that the sulfur removal slag has a porous property, and sulfur can be removed relatively uniformly. Thus, from the viewpoint of an increased reaction area between the slag and gas, a porous slag property is considered important for accelerating the sulfur removal reaction. Consideration of the sulfur removal rate from hot metal desulfurization slag and the required treatment time are issues for future work.

\subsection{Desulfurization Capacity of Sulfur Removal Slag}

As shown in Fig. 6, when using the sulfur removal slag, the sulfur content after 900 seconds was the same as that when using virgin flux. However, until 240 seconds after flux addition, the desulfurization rate tends to be slightly lower when using the recycled sulfur removal slag.

Assuming that the rate-controlling step of the desulfurization reaction is the mass transfer of $[\mathrm{S}]$ in the boundary film on the hot metal side, the desulfurization rate can be expressed as shown in Eq. (13). ${ }^{16)}$ The change in the apparent desulfurization rate constant $K(1 / \mathrm{min})$ evaluated at each sampling time under this assumption is shown in Fig. 10.

$$
-\frac{d[\operatorname{mass} \% S]}{d t}=K \cdot[\operatorname{mass} \% S] \text {. }
$$

It can be understood that the apparent desulfurization rate constant $K$ until 240 seconds after flux addition with the recycled sulfur removal slag No. H-1 is lower than that with the virgin flux. The slag compositions after the hot metal desulfurization experiments are shown in Table 2. It can be seen that the $\mathrm{SiO}_{2}$ content in the slag is higher with No. H-1 than with No. H-2. It is considered possible that the desulfurization rate constant decreases when recycling the sulfur removal slag because $\mathrm{SiO}_{2}$ reacts with $\mathrm{CaO}$ to form some compounds, and this reduces the effective amount of 

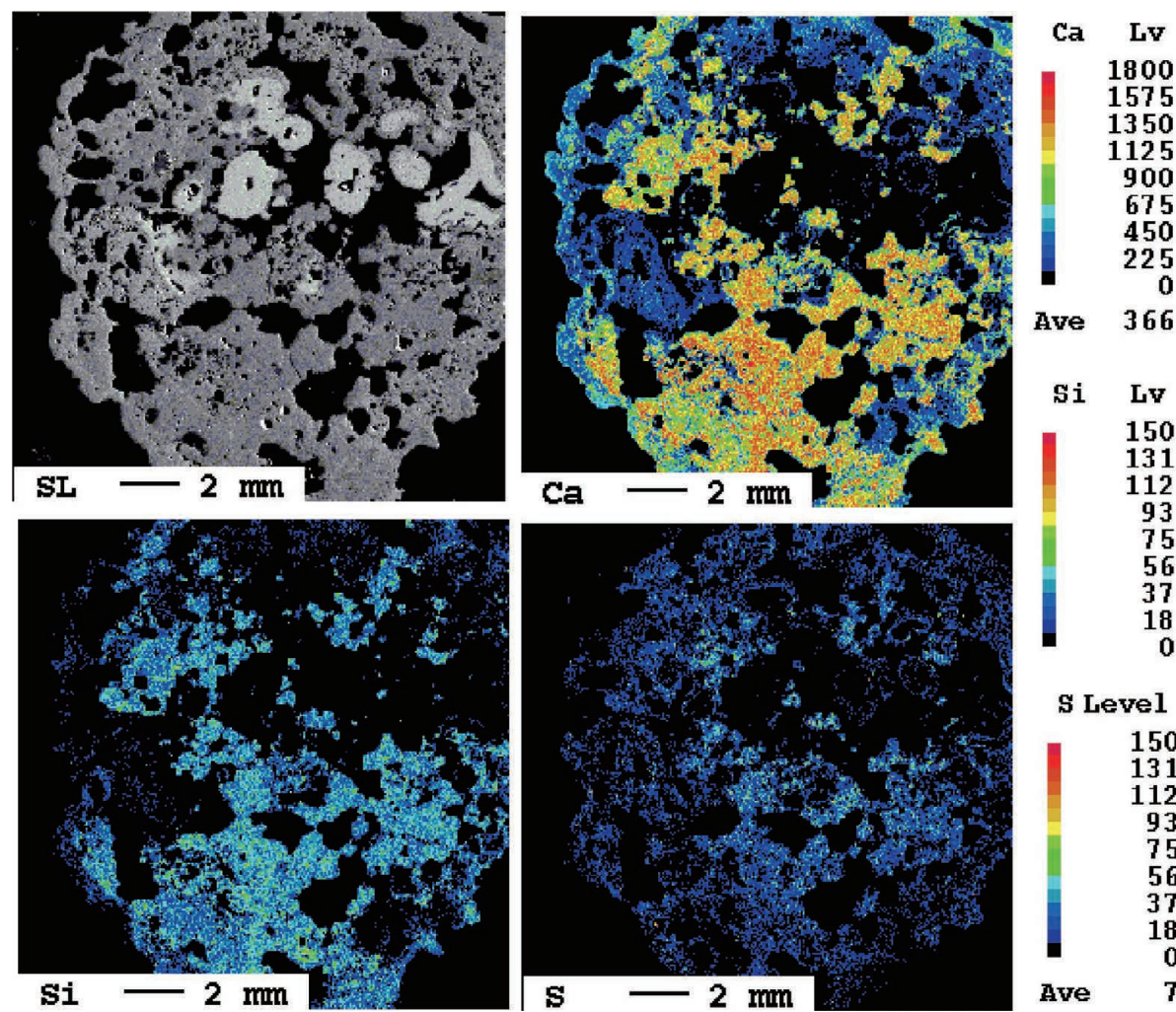

Si Lv

150

131

112

93

56

56
37

37
18

S Level

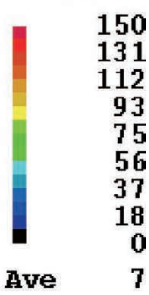

Fig. 9. EPMA mapping image of slag after sulfur removal treatment.

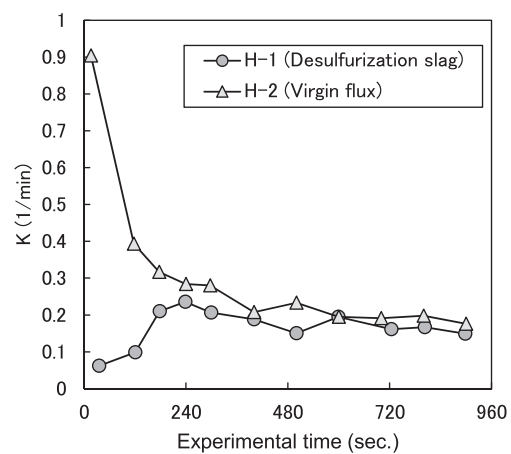

Fig. 10. Behavior of desulfurization rate constant $K$.

Table 2. Slag composition after hot metal desulfurization experiments.

\begin{tabular}{cccccc}
\hline & $\begin{array}{c}\mathrm{CaO} \\
\text { mass\% }\end{array}$ & $\begin{array}{c}\mathrm{SiO}_{2} \\
\text { mass\% }\end{array}$ & $\begin{array}{c}\mathrm{Al}_{2} \mathrm{O}_{3} \\
\text { mass\% }\end{array}$ & $\begin{array}{c}\mathrm{MgO} \\
\text { mass\% }\end{array}$ & $\begin{array}{c}\mathrm{T} . \mathrm{Fe} \\
\text { mass\% }\end{array}$ \\
\hline $\begin{array}{c}\mathrm{H}-1 \\
\text { (Desulfurization slag) }\end{array}$ & 63.21 & 14.1 & 2.35 & 3.02 & 11.3 \\
$\begin{array}{c}\mathrm{H}-2 \\
\text { (Virgin flux) }\end{array}$ & 71.45 & 7.43 & 1.33 & 2.33 & 10.6 \\
\hline
\end{tabular}

\section{$\mathrm{CaO}$ for desulfurization.}

Nakai et al. ${ }^{17)}$ considered the effect of the $\mathrm{SiO}_{2}$ content in recycled slag on the utilization efficiency of the recycled slag in experimental research. The desulfurization rate constant $K$ was directly compared with that of Nakai et al., since the experimental conditions of this study were almost the same as in Nakai et al. The relationship between the $\mathrm{SiO}_{2}$ content in the slag after the desulfurization experiment and the desulfurization rate constant $K$ is shown in Fig. 11. The lines in Fig. 11 indicate the desulfurization rate constant

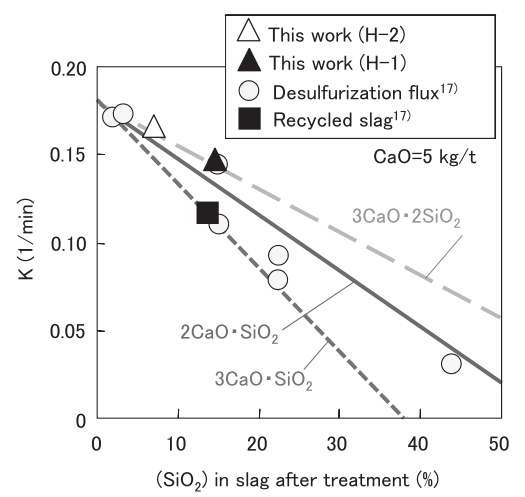

Fig. 11. Effect of $\left(\mathrm{SiO}_{2}\right)$ content in slag on desulfurization rate constant $K$.

$K$ calculated under the assumption that the effective $\mathrm{CaO}$ for desulfurization decreases because the $\mathrm{CaO}$ in the slag reacts with $\mathrm{SiO}_{2}$ to form compounds. In this case, it is assumed that the desulfurization rate constant is proportional to the effective amount of $\mathrm{CaO}$.

As in the consideration by Nakai et al., the results of the present research show that the desulfurization rate constant tends to decrease as the $\mathrm{SiO}_{2}$ content in the slag increases. Therefore, when recycling sulfur removal slag, the amount of flux addition should be determined considering an increase in the amount of $\mathrm{SiO}_{2}$ in the slag. However, the results of Nakai et al. follow the line estimated from the formation of a $3 \mathrm{CaO} \cdot \mathrm{SiO}_{2}$ compound, whereas the results of this study follow the line estimated from the formation of a $3 \mathrm{CaO} \cdot 2 \mathrm{SiO}_{2}$ compound. As one of the factors in this difference, it is considered that the comparative apparent effective amount of $\mathrm{CaO}$ in this study may increase, since the particle size of the recycled slag in this study was set to $0.25 \mathrm{~mm}$ or less, whereas that in the experiments by Nakai 
et al. was set to $-1 \mathrm{~mm}-+10 \mathrm{~mm}$. Quantitative analysis on this point is a subject for future work.

As shown in Fig. 10, the apparent desulfurization rate constants of No. H-1 and H-2 after 240 seconds from flux addition were almost same. In the desulfurization process with mechanical stirring, the particle size of the desulfurization flux increases with reaction time due to aggregation. ${ }^{18)}$ After 240 seconds from flux addition, it is estimated that the desulfurization rates of No. $\mathrm{H}-1$ and $\mathrm{H}-2$ are almost same since the interfacial area between flux and hot metal decreases as the particle size of the desulfurization flux increases. A detailed investigation of the reaction mechanism is required in the future.

\section{Conclusions}

A technique for removal of sulfur from hot metal desulfurization slag and reuse of the sulfur removal slag in the hot metal desulfurization process were investigated in laboratory hot model experiments. The conclusions are summarized as follows.

(1) Based on the results of the sulfur removal experiments from $\mathrm{CaS}$ and $\mathrm{CaSO}_{4}$ reagents, the sulfur removal ratio from $\mathrm{CaS}$ improved with a higher oxygen potential, whereas that from $\mathrm{CaSO}_{4}$ improved with a lower oxygen potential.

(2) In the results of the sulfur removal experiments from hot metal desulfurization slag, a sulfur removal ratio exceeding $90 \%$ was obtained under the conditions of a temperature range of $1473-1673 \mathrm{~K}$ and an oxygen potential range of $10^{-3}-10^{-8} \mathrm{~atm}$.

(3) The results of thermodynamic calculations of the sulfur stable phase showed that $\mathrm{SO}_{\mathrm{X}}$ gas and $\mathrm{CaO}$ can coexist stably in a temperature range of 1 473-1 $673 \mathrm{~K}$ and an oxygen potential range of $10^{-3}-10^{-8} \mathrm{~atm}$. The appropriate temperature and oxygen potential for sulfur removal from hot metal desulfurization slag can be determined by thermo- dynamic calculations.

(4) Based on the results of the hot metal desulfurization experiments using recycled sulfur removal slag, the sulfur content achieved after 900 seconds with the sulfur removal slag was approximately the same as that when using virgin flux under the condition of the same unit consumption of $\mathrm{CaO}$. Thus, it is considered possible to recycle sulfur removal slag as a lime source for the hot metal desulfurization process.

\section{REFERENCES}

1) K. Kanbara, T. Nisugi, O. Shiraishi and T. Hatakeyama: Tetsu-toHagané, 58 (1972), 34.

2) Y. Nakai, I. Sumi, H. Matsuno, N. Kikuchi and Y. Kishimoto: ISIJ Int., 50 (2010), 403.

3) A. Matsui, Y. Nakai, N. Kikuchi, Y. Miki, S. Sato, R. Kawabata and A. Ichikawa: Tetsu-to-Hagané, 99 (2013), 458.

4) K. Horii, N. Tsutsumi, Y. Kitano and T. Kato: Nippon Steel Tech. Rep., 104 (2013), 123.

5) H. Ooi: J. Jpn. Inst. Met., 22 (1983), 695.

6) Y. Nakai, S. Nabeshima, Y. Kishimoto, S. Tanaka, J. Shiino and C. Taki: CAMP-ISIJ, 19 (2006), 831.

7) T. Mori, A. Moro-oka and H. Kokubu: Tetsu-to-Hagané, 69 (1983), 582.

8) J. Kobayashi, S. Urubata, K. Matsubae and T. Nagasaka: CAMP-ISIJ, 21 (2008), 937, CD-ROM

9) J. Kobayashi, K. Matsubae and T. Nagasaka: CAMP-ISIJ, 22 (2009), 94, CD-ROM.

10) S. Nagata, K. Yamamoto, T. Yokoyama and S. Shiga: Mem. Fac. Eng., Kyoto Univ., 19 (1957), 274.

11) The 19th Committee on Steelmaking: Steelmaking Data Sourcebook Rev. ed., JSPS, Tokyo, (1984), 49, 254.

12) C. W. Bale, E. Belisle, P. Chartrand, S. A. Decterov, G. Eriksson, K. Hack, I. H. Jung, Y. B. Kang, J. Melancon, A. D. Pelton, C. Robelin and S. Petersen: Calphad, $\mathbf{3 3}$ (2009), 295.

13) Thermfact and GTT-Technologies: FactSage, www.factsage.com, (accessed 2011-08-15).

14) N. Sano, W. K. Lu, P. V. Riboud and M. Maeda: Advanced Physical Chemistry for Process Metallurgy, Academic Press, San Diego, (1997), 57

15) R. H. Borgwardt: Environ. Sci. Technol., 4 (1970), 59.

16) K. Nakanishi, N. Bessho, S. Takada, A. Ejima, M. Kuga, J. Katsuki and M. Kawana: Tetsu-to-Hagané, 64 (1978), 1528.

17) Y. Nakai, N. Kikuchi, M. Iwasa, S. Nabeshima and Y. Kishimoto: Steel Res. Int., 80 (2009), 727.

18) Y. Nakai, I. Sumi, N. Kikuchi, Y. Kishimoto and Y. Miki: ISIJ Int., 53 (2013), 1411. 